\title{
Development of a Manual Assembly Line for a 950kw Single Stroke Generator
}

\author{
Oladeinde M. H. ${ }^{1}$ and Edokpia R.O. ${ }^{1, *}$ \\ ${ }^{1}$ Department of Production Engineering, University of Benin, Benin City, Nigeria \\ Corresponding Author: *ralphedokpia@yahoo.com
}

\begin{abstract}
In this paper, a manual assembly line for the assembly of a 950KW gasoline generator has been designed. A part list of a purchased generator was generated after the machine was disassembled. Work measurement technique was used to generate an assembly process for the machine. The duration for assembly of each component was obtained using stop watch and then standardized. The cycle time of the manual assembly line was determined and subsequently, the distribution of load amongst the ten station line was balanced out using the ranked positional weight technique. Computations reveal that a fairly high labour efficiency of 0.804 is obtained. The line balancing efficiency obtained equal 0.849 implying a balance delay of 0.151.
\end{abstract}

Keywords: Manual assembly line, line balancing, ranked positional weight, generator, cycle time, efficiency

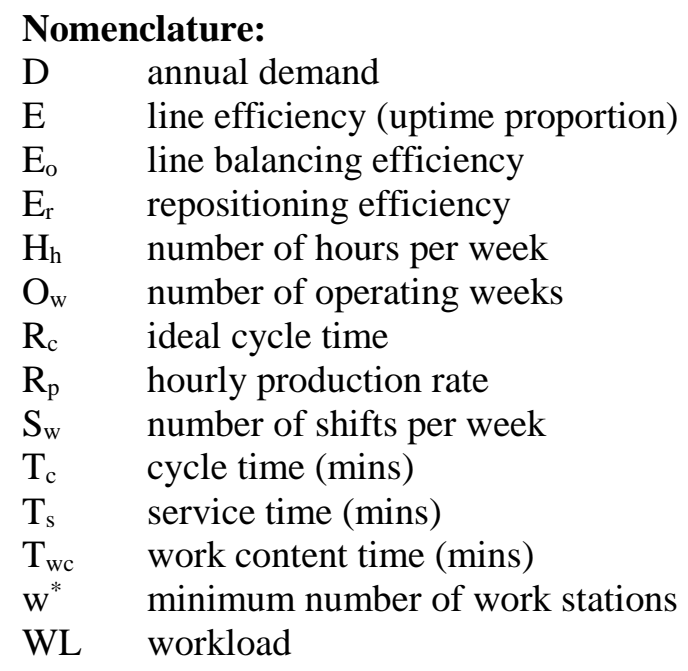

\subsection{Introduction}

Epileptic public power supply and household quest to obtain power from alternative sources has become a daily occurrence in Nigeria according to Olaleye and Akinbode (2012). The reliance of most households on power supply using the $950 \mathrm{Kw}$ generator has continued to increase. The Nigerian economy is predominantly middle class; consequently purchase of heavy duty generating sets is beyond their reach. The $950 \mathrm{Kw}$ gasoline generator popularly known as "I better pass my neighbor" is available in most households in Nigeria. The major reason advanced for its purchase is its fuel economy and portability. Currently, the assembly of generators is done in a single station manual assembly cell. A single workstation is one in which all of the assembly work is accomplished on the product or on some major subassembly. Even though this practice is known to result in greater worker satisfaction, it is comparatively slower than line production. Consequently, the need to develop multi station manual assembly line for the assembly of the generators is evident. In spite of the major advances in the 
automation of assembly processes, there are still many assembly systems which mainly or completely rely on manual labour

Lit and Delchambre (2011) stated that assembly lines are the most commonly used method in mass production environments because they enable assembly of complex products by workers with limited training. An assembly line consists of workstations that produce a product as it moves successively from one workstation to the next along the line (Hamza and Al-Manaa, 2013). The cardinal purpose of assembly systems designers is to increase production line efficiency by optimizing the ratio between throughput and required costs. This is achieved by ensuring that the workload is distributed amongst the various stations in an even way. Line balancing is an effective tool to improve the throughput of assembly line while reducing non- value-adding activities and cycle time. Amardeep et al (2013) stated that line balancing is the problem of assigning operation (s) to workstation along an assembly line in such a way that assignment is optimal in some sense. Additionally, Salveson (1995) described the assembly line balancing problem (ALBP) as assigning tasks to an ordered sequence of stations such that the precedence relations among the tasks are satisfied and some performance measure is optimized.

Many previous approaches to analyzing and developing the performance of assembly systems such as the works of Eryuruk et al (2008), Kamlekar et al ((2012), Edokpia and Okonta(2013) and Edokpia and Owu (2013), have focused on the balancing and rebalancing of existing assembly systems. According to Kitaw et al (2010), balancing refers to the procedure of adjusting the operation times at work centers to conform as much as possible to the required cycle time. A few studies have focused on generating empirical data for subsequently developing and analyzing manual assembly lines. One of the most important approaches to studying line balancing with work stations characterized by manual operations is work measurement according to Longo et al (2006). A key step in the development of a manual assembly line is the preparation of a Work Standard. A Work Standard is a list of all the assembly operations that have to be performed to produce a finished product, with each of the operations taking place at a different position along the assembly line.

In this study, method study and work measurement techniques have been used to obtain a precedence relationship among the various tasks necessary for the complete assembly of a $950 \mathrm{Kw}$ gasoline generator. The task times have also been standardized to account for the variability in task times due to differences in skill level of human operators. The developed manual assembly line was balanced using the ranked positional weight technique and operating characteristics of the line determined.

\subsection{Methodology}

In this section, the methodology for the development of the manual assembly line for $950 \mathrm{Kw}$ gasoline generators is presented. The first step was to completely disassemble all the components necessary to assemble all the parts and sub-assemblies of the gasoline generator. A list of part names of the generator was developed. Method study technique was subsequently used to develop an assembly procedure for the generator. The assembly procedure established was then used to completely assemble the various components by three different operators who have had at least 5 years' experience in generator repair and a stop watch used to determine the times taken to perform the various work elements necessary for the complete assembly of a complete unit of the generator. The mean of the three observed times was recorded as the task assembly time for each component. Certain constraints were considered in the course of assembling the generator. They are;

i. Creation of sub-assemblies components of the gasoline generator

ii. A Sub-assembly is generated only when sensitive properties of that part are paramount to the functionality of the generator and must not be damage by human hands and excessive force. The sub-assemblies were carburettor assembly, dash-board assembly, and crank-shaft part.

iii. Each component of the generator has a corresponding assembly task to be performed.

iv. Only one single operation can be performed at a time

v. A part can only be assembled to the whole if the initial assemblage has an interconnecting side with that component 


\subsection{Standardization of Task Times}

The use of standard times which accounts for the fact that workers have great variations in level of skill and aptitudes for certain jobs. A performance rating of $115 \%$ was used to convert the observed times to normal times. A total allowance of $20 \%$ was made to the normal times leading to the standard times used for the analysis of the manual assembly line. The standardized task times are presented in Table 2.

\subsection{Generator Part List}

The generator was carefully stripped and a part list of the various components, assembly and subassemblies drawn up. The part list is presented in Table 1

Table 1: Part description of the 950kw Gasoline Generator

\begin{tabular}{cl|cl}
\hline Part Number & Part Names & Part Number & Part Names \\
\hline 1 & Crank shaft and bearings & 15 & Inlet valve \\
2 & Left crank casing & 16 & Carburetor \\
3 & Right crank casing & 17 & Throttle and springs \\
4 & Motor coil & 18 & Dash board \\
5 & Armature & 19 & Dash board/panel cover \\
6 & Armature cover & 20 & Flywheel-starter coil \\
7 & Piston rings & 21 & Flywheel \\
8 & Engine block & 22 & Recoil starter/pulley/spring \\
9 & Engine-cylinder packing & 23 & CDI \\
10 & Top cylinder & 24 & Capacitor/switch \\
11 & Spark plug & 25 & Socket \\
12 & Exhaust & 26 & Stator wires \\
13 & Engine cover & 27 & Ignition coil \\
14 & Inlet Valve packing & 28 & Fuel tank \\
\hline
\end{tabular}

Table 2: Standard times of the tasks

\begin{tabular}{ccl}
\hline Task Number & Standard Time [seconds] & Process description \\
\hline 1 & 66 & Crank shaft assembly \\
2 & 146 & Assemble left crank case on shaft \\
3 & 123 & Assemble right casing \\
4 & 45 & Assemble motor coil inside Crank case \\
5 & 83 & Insert armature \\
6 & 148 & Assemble Armature cover \\
7 & 31 & Put rings on piston \\
8 & 106 & Assemble engine block \\
9 & 12 & Put cylinder packing \\
10 & 108 & Assembly top cylinder \\
11 & 17 & Tighten spark plug into engine subassembly \\
12 & 70 & Assemble exhaust \\
13 & 44 & Assemble engine cover \\
14 & 12 & Place valve packing on half engine \\
15 & 73 & Assemble inlet valve on crank case \\
16 & 33 & Attach carburetor to inlet valve. \\
17 & 18 & Connect throttle to carburetor \\
18 & 110 & Assembly dash board-carburetor subsystem on valve \\
19 & 19 & Place panel cover \\
20 & 33 & Assemble chassis into half engine \\
21 & 71 & Assembly flywheel \\
22 & 95 & Assemble starter cap \\
23 & 17 & Connect CDI and flywheel/ switch \\
24 & 18 & Connect CDI and motor coil wire \\
25 & 15 & Connect coil wire to capacitor/socket \\
26 & 21 & Connect flywheel starting coil and motor coil \\
27 & 21 & Connect ignition coil on spark plug \\
28 & 207 & Assembly Fuel tank \\
& & \\
\hline
\end{tabular}

A flowchart showing the sequence in which the assembly work takes place in the manual assembly line is shown in Figure 1. 


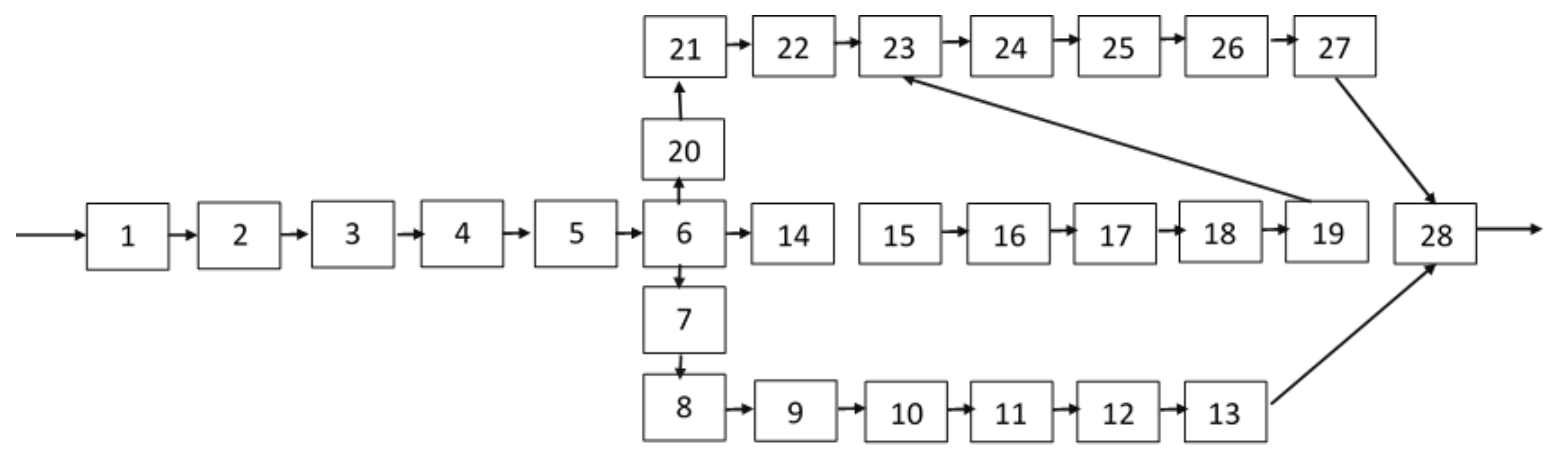

Figure 1: flowchart showing assembly process of assembly of assembly line

\subsection{Theoretical Considerations}

\subsubsection{Production Rate}

The manual assembly line must be designed for a particular value of annual demand $D$. Assuming the following notation for line operational characteristics; $S_{w}=$ number of shifts per week, $H_{h}=$ number of hours per shift, $O_{w}=$ number of operating weeks, the hourly production rate $R_{p}$ which guarantees the annual demand is calculated using

$$
R_{p}=\frac{D_{a}}{S_{w} O_{w} H_{h}}
$$

The production rate can be converted cycle time using the Equation. (2).The determination of the cycle time in Equation (2) accounts for the inevitability of production time losses due to a myriad of issues relating to for example labour problems, equipment failures and power outages. Consequently, only a proportion of the shift time will be available. Line efficiency (uptime proportion) for manual production, E, assumes values in the range 0.9-0.98 according to Groover (2008).

$$
T_{c}=\frac{60 E}{R_{p}}
$$

The cycle time obtained in Equation (2) is related to the ideal cycle time of the line by Equation (3)

$$
R_{c}=\frac{60}{T_{p}}
$$

The line efficiency E can be calculated as

$$
E=\frac{R_{p}}{R_{c}}=\frac{T_{c}}{T_{p}}
$$

The workload to be accomplished $(W L)$ is related to the production rate $\left(R_{p}\right)$ and the work content time $\left(T_{w c}\right)$, defined as the total time of all work elements that must be performed to produce one unit of the work unit, by the expression

$$
W L=R_{p} T_{w c}
$$

The theoretical minimum number of stations that will be required on the line to produce one unit of the work unit $w^{*}$ is computed using

$$
w^{*}=\text { minimum integer } \geq \frac{T_{w c}}{T_{c}}
$$




\subsection{Analysis of Results and Discussion}

\subsection{Analysis of Single Model Assembly Line}

The manual production line was designed for a total production volume of complete units of the complete generator per annum. According to the nomenclature adopted $D_{a}=32,000$. The annual demand designed for will be obtained for 50 weeks working year, 5 working days per week and 8 working hours per day.

Based on the design data and using Equation (1), the production rate which guarantees the annual production volume is;

$$
R_{p}=\frac{32000}{50 \times 5 \times 8}=16 \text { units per hour }
$$

The total work content $\left(T_{w c}\right)$ of the assembly process is a summation of all the task times is;

$$
T_{w c}=\sum_{i=1}^{28} T_{i}=30 \text { minutes }
$$

The minimum number of stations $\left(w^{*}\right)$ required to produce one unit of the product assuming uptime efficiency $(E)=0.96$ is

$$
\begin{aligned}
& w^{*}=\text { minimum integer } \geq \frac{R_{p} T_{w c}}{60 E} \geq \frac{16 \times 29.91}{60 \times 0.96} \\
& w^{*}=9 \text { stations }
\end{aligned}
$$

The cycle time $\left(T_{c}\right)$ of the assembly process is determined by Equation (2)

$$
T_{c}=\frac{60 \times 0.96}{16}=3.6 \text { minuites }
$$

Assuming that the time required to move the product from one work station to the adjacent work station $\left(T_{r}\right)$ is 4 seconds, the service time $\left(T_{s}\right)$ which is the available time in each cycle for the worker to work on the product is equal to

$$
T_{s}=T_{c}-T_{r}=3.6-0.05=3.55 \text { minutes }
$$

The available time for work is therefore 213 seconds at each station.

\subsection{Line Balancing Using Rank Positional Weight}

A cycle time of 216 seconds has been determined from the previous section. The tasks needed to completely assemble a unit of the generator have been arranged according to their positional weights from the highest to the least and is presented in Table 3.

Based on the tabulation of the tasks Rank Positional Weights, the manual assembly line has been balanced with a cycle time of 213 seconds. The tasks in each station, total station time as well as idle time is presented in Table 4 
Table 3: Ranked position weights of tasks

\begin{tabular}{cccc}
\hline Task & Task duration [seconds] & RPW & Predecessor \\
\hline 1 & 66 & 1802 & - \\
2 & 146 & 1736 & 1 \\
3 & 163 & 1590 & 2 \\
4 & 45 & 1427 & 3 \\
5 & 83 & 1382 & 4 \\
6 & 148 & 1299 & 5 \\
7 & 31 & 595 & 6 \\
8 & 106 & 564 & 7 \\
14 & 12 & 547 & 6 \\
15 & 73 & 535 & 14 \\
20 & 33 & 498 & 6 \\
21 & 71 & 465 & 20 \\
16 & 33 & 462 & 15 \\
9 & 12 & 458 & 8 \\
10 & 108 & 446 & 9 \\
17 & 18 & 429 & 16 \\
18 & 110 & 411 & 17 \\
22 & 95 & 394 & 21 \\
11 & 17 & 338 & 10 \\
12 & 70 & 321 & 11 \\
19 & 19 & 301 & 18 \\
23 & 17 & 299 & 18,22 \\
24 & 18 & 282 & 23 \\
25 & 15 & 264 & 24 \\
13 & 44 & 251 & 12 \\
26 & 21 & 249 & 25 \\
27 & 21 & 228 & 13,16 \\
28 & 207 & 207 & 27 \\
\hline & & &
\end{tabular}

Table 4: Works stations showing tasks and total station time

\begin{tabular}{|c|c|c|c|}
\hline Station Number & Tasks & Task times & Station time \\
\hline \multirow{2}{*}{1} & 1 & 66 & \multirow{2}{*}{212} \\
\hline & 2 & 146 & \\
\hline \multirow{2}{*}{2} & 3 & 163 & \multirow{2}{*}{208} \\
\hline & 4 & 145 & \\
\hline 3 & 5 & 83 & 83 \\
\hline \multirow{3}{*}{4} & 6 & 148 & \multirow{3}{*}{191} \\
\hline & 7 & 31 & \\
\hline & 14 & 12 & \\
\hline \multirow{3}{*}{5} & 8 & 106 & \multirow{3}{*}{212} \\
\hline & 15 & 73 & \\
\hline & 20 & 33 & \\
\hline \multirow{4}{*}{6} & 21 & 71 & \multirow{4}{*}{134} \\
\hline & 16 & 33 & \\
\hline & 9 & 12 & \\
\hline & 17 & 13 & \\
\hline \multirow{2}{*}{7} & 10 & 108 & \multirow{2}{*}{203} \\
\hline & 22 & 95 & \\
\hline \multirow{3}{*}{8} & 18 & 110 & \multirow{3}{*}{197} \\
\hline & 11 & 17 & \\
\hline & 12 & 70 & \\
\hline \multirow{7}{*}{9} & 19 & 19 & \multirow{7}{*}{155} \\
\hline & 23 & 17 & \\
\hline & 24 & 18 & \\
\hline & 25 & 15 & \\
\hline & 13 & 44 & \\
\hline & 26 & 21 & \\
\hline & 27 & 21 & \\
\hline 10 & 28 & 207 & 207 \\
\hline
\end{tabular}


The repositioning efficiency $\left(E_{r}\right)$ of the line is

$$
E_{r}=\frac{3.55}{3.60}=.0 .986
$$

The line balancing efficiency $\left(E_{0}\right)$ is determined as

$$
E_{o}=\frac{30}{10 \times 3.53}=0.849
$$

The balance delay of the assembly line is therefore 0.151 .

Using the uptime efficiency, repositioning efficiency and the line balancing efficiency, the labour efficiency of the assembly line is computed to be

$$
\text { labour efficiency }=0.96 \times 0.986 \times 0.849=0.804
$$

Using the computed value of labour efficiency, a more realistic value of the number of workers on the assembly line is

$$
w=\text { minimum integer } \geq \frac{30}{0.849 \times 3.55}=10
$$

\subsection{Discussion of Results}

The manual assembly line designed has a maximum production volume of 32000 units per annum. This annual production volume is achievable by hourly production rate of 16 complete units per hour. Extensive experimentation shows that on the average it takes about half an hour to completely assemble a unit of the generator. Theoretical analysis put forward that a minimum of nine work stations is required to assemble the product. Based on a cycle time of 213 seconds which took into account repositioning time as well four seconds provision for transporting the semi-finished product from one station to the adjacent station, line balancing using the ranked positional weight technique yielded a total of 10 work stations, each manned by a worker. The line and labour efficiencies computed for the line based on the operating conditions were 0.849 and 0.804 respectively. These values are fairly high and demonstrate an attractive productivity for the designed assembly line.

\subsection{Conclusion}

The key output of this research is the design of a manual assembly system for assembly of a commonly used petrol generator. The serial ten station assembly line is manned by one worker per station. The tasks to be carried out at each work station have been determined using the ranked positional weight technique. The line efficiency determined is meritorious showing potential of high worker productivity.

\section{References}

Amardeep, T. Rangaswamy, M. and Gautham, J. (2013) Line Balancing of Single Model Assembly Line, International Journal of Innovative Research in Science, Engineering and Technology 2(5) pp. $1678-1680$.

Edokpia, R.O. and Okonta, C.I. (2013) Solving Assembly Line Balancing Problems: A Case Study of a Manufacturing Company. J. Nig. Assoc. Math. Phys. 25(1) pp. 251-266.

Edokpia, R.O. and Owu, F.U. (2013) Assembly Line Rebalancing Using Ranked Positional Weight Technique and Longest Operating Time Technique: A Comparative Analysis, J. Adv. Matls. Res. 824 pp. 568-578. 
Eryuruk, S.H., Kalaoglu, F. and Baskak, M. (2008) Assembly Line Balancing in a Clothing Company, J. Fibres and Textiles in Eastern Europe, 16 93-98.

Groover, M.P. (2008) Automation, Production Systems, and Computer-Integrated Manufacturing, 3rd Edition, Prentice Hall, New Jersey.

Hamza, R.M.A. and Al-Manaa, J.Y. (2013) Selection of Balancing Method for Manual Assembly Line of Two Stages Gearbox, Global Perspectives on Engineering Management , 2(2) pp.70-81.

Kamlekar, N., Gupta, R.C. and Dalpati, A. (2012) Implementation of Assembly Line Balancing in a Labour Intensive Manufacturing Unit, National Conference on Emerging Challenges for Sustainable Business 1720-1730.

Kitaw, D., Matebu, A. and Tadesse, S. (2010) Assembly Line Balancing Using Simulation Technique In A Garment Manufacturing Firm. Journal of EEA, 27, $69-80$.

Lit, P.D. and Delchambre, A. (2011) Integrated Design of a Product family and its assembly system, Kluwer Academic Publishers group, The Netherlands

Longo, F., Mirabelli, G. and Papoff, E. (2006) Effective Design Of An Assembly Line Using Modeling $\&$ Simulation, Proceedings of the Winter Simulation Conference.

Olaleye, S.O. and Akinbode, S.O. (2012)Analysis of Households' Demand for Alternative Power Supply in Lagos State, Nigeria, Current Research Journal of Social Science 4(2) pp. 121-127.

Salveson, M.E. (1995) The assembly line balancing problem, Journal of Industrial Engineering 6(3) pp.18-25. 